\title{
Three-Dimensional Numerical Method for Supercritical Heat Transfer of Hydrocarbon Fuels
}

\author{
Guozhu Zhao ${ }^{1}$, Wenyan Song ${ }^{1} \&$ Ruoling Zhang ${ }^{2}$ \\ ${ }^{1}$ School of Power and Energy, Northwestern Polytechnical University, Xi'an, China \\ ${ }^{2}$ Science and Technology Laboratory on Scramjet, China Aerodynamics Research and Development Center, \\ Mianyang, China \\ Correspondence: Guozhu Zhao, Science and Technology Laboratory on Scramjet, No. 278, Jianmen Road, \\ Mianyang, China. E-mail: dfer-long@163.com
}

Received: November 27, 2014 Accepted: December 15, 2014 Online Published: January 6, 2015

doi:10.5539/apr.v7n1p64 URL: http://dx.doi.org/10.5539/apr.v7n1p64

\begin{abstract}
In order to study the regenerative cooling mechanism, a three-dimensional numerical method for supercritical heat transfer of hydrocarbon fuels was established based on the Navier-Stokes equations and a thermophysical properties evaluation code. The supercritical heat transfer behavior of $n$-decane inside an electrically heated tube and $n$-dodecane inside a fuel-cooled panel has been computed. Detailed distributions of outer wall temperature and fuel temperature were obtained. The corresponding measurements are adopted to validate the numerical method. The relative deviations of the computational outer wall temperature from the test results are within $6.8 \%$, and those of the fuel temperature are within $1 \%$. Those indicate that the numerical method is reliable, and can be used as an effective tool to investigate the supercritical heat transfer of hydrocarbon fuels.
\end{abstract}

Key words: hydrocarbon fuels, numerical method, regenerative cooling, supercritical

\section{Introduction}

Supercritical heat transfer of hydrocarbon fuels plays a key role in the regenerative cooling process for scramjet (Palaszewski, Ianovski \& Carrick, 1998; Huang, Spadaccini, \& Sobel, 2004). The combustor wall of scramjet combustor endures high heat flux from the high temperature gases. In order to maintain engine reliability and lifetime, the fuel is firstly injected into the cooling channels in the wall panels and then into the combustor. On this occasion, the combustor wall is cooled via the convective heat transfer of fuel, and the heat energy is reused. The cross section of cooling channels is rectangular. The wall panels are heated one-sidedly. Therefore, the flow and heat transfer of hydrocarbon fuel in the cooling channels need a three-dimensional computational tool to be investigated.

The working pressure of the fuel generally exceeds its critical pressure. The properties of hydrocarbon fuel change acutely in the vicinity of the critical point, and the heat transfer behavior under supercritical conditions could exhibit much different features from that under subcritical conditions. Drastic changes in the heat transfer characteristics as the hydrocarbon fuel approach its critical state, and heat transfer enhancement after the fuel temperature became supercritical were observed (Zhong et al., 2008). Meanwhile, heat transfer deterioration could occur once the fuel temperature reaches the pseudo-critical temperature (Hua, Wang, \& Meng, 2010; Dang, Zhong, Chen, \& Zhang, 2013). These studies show that detailed investigation of supercritical heat transfer of hydrocarbon fuels is needed.

In this paper, a three-dimensional numerical method for supercritical heat transfer of hydrocarbon fuels was established based on the Navier-Stokes (N-S) equations and a thermophysical properties evaluation code. The electrically heated tube and fuel-cooled panel experiments were conducted to validate the numerical method.

\section{Computation Method}

\subsection{Governing Equations}

The heat transfer characteristics in solid wall could have significant effect on the flow and heat transfer behaviors of hydrocarbon fuels flowing in the cooling channels. A computation method of fluid-solid conjugated heat transfer is needed. 
Solid thermal conduct equation:

$$
\frac{\partial}{\partial x_{j}}\left(k_{s} \frac{\partial T}{\partial x_{j}}\right)=0
$$

The $k_{s}$ and $T$ are solid thermal conductivity and temperature respectively.

Flow and heat transfer of hydrocarbon fuel in cooling channels are described by Navier-Stokes equations.

Mass conservation equation:

$$
\frac{\partial}{\partial x_{j}}\left(\rho u_{j}\right)=0
$$

Momentum conservation equation:

$$
\frac{\partial}{\partial x_{j}}\left(\rho u_{i} u_{j}\right)=-\frac{\partial p}{\partial x_{j}}+\frac{\partial}{\partial x_{j}}\left(\mu_{e f f} \frac{\partial u_{i}}{\partial x_{j}}\right)+\frac{\partial}{\partial x_{j}}\left(\mu_{e f f}\left(\frac{\partial u_{i}}{\partial x_{j}}-\frac{2}{3} \delta_{i j} \frac{\partial u_{k}}{\partial x_{k}}\right)\right)
$$

Energy conservation equation:

$$
\frac{\partial}{\partial x_{j}}\left(\rho u_{j} h\right)=\frac{\partial}{\partial x_{j}}\left(\alpha_{e f f} \frac{\partial h}{\partial x_{j}}\right)+u_{j} \frac{\partial p}{\partial x_{j}}+\Phi
$$

In Equations (2)-(4), the $\rho, u, p$ and $h$ represent fluid density, velocity, pressure and enthalpy respectively. The $\mu_{e f f}$ and $\alpha_{\text {eff }}$ are effective viscosity coefficient and effective thermal diffusion coefficient respectively. The $\Phi$ is the viscous dissipation term.

The $k$ - $\omega S S T$ model is directly applicable in near-wall region and therefore avoids the implementation of an uncertain wall function (Menter, 1994), and is chosen to compute the turbulent flow and heat transfer. The turbulent equations are defined by Equations (5) and (6).

$$
\begin{gathered}
\frac{\partial\left(\rho u_{j} k\right)}{\partial x_{j}}=P_{k}-D_{k}+\frac{\partial}{\partial x_{j}}\left(\left(\mu+\alpha_{k} \mu_{t}\right) \frac{\partial k}{\partial x_{j}}\right) \\
\frac{\partial\left(\rho u_{j} \omega\right)}{\partial x_{j}}=\frac{\gamma \rho}{\mu_{t}} P_{k}+\frac{\partial}{\partial x_{j}}\left(\left(\mu+\alpha_{\omega} \mu_{t}\right) \frac{\partial \omega}{\partial x_{j}}\right)-\beta \rho \omega^{2}+\left(1-F_{1}\right) \frac{2 \rho \alpha_{\omega 2}}{\omega} \frac{\partial k}{\partial x_{j}} \frac{\partial \omega}{\partial x_{j}}
\end{gathered}
$$

In Equations (5) and (6), the $k$ and $\omega$ are turbulent kinetic energy and specific dissipation rate respectively. The $P_{k}$ and $D_{k}$ are production and dissipation terms of $k$. Detailed descriptions of $k$ - $\omega S S T$ model can be found in Menter's paper (1994).

On the fluid-solid interface, an algorithm of sub-regional is adopted to compute the fluid-solid conjugated heat transfer. The temperature and heat flux must be continuous on the interface, that is:

$$
\left.T_{w}\right|_{s}=\left.T_{w}\right|_{f},\left.\quad q_{w}\right|_{s}=\left.q_{w}\right|_{f}
$$

The subscripts $w, s$ and $f$ represent the wall, solid and fluid respectively.

\subsection{Thermophysical Properties Evaluation for Hydrocarbons}

Accurate evaluation of the thermophysical properties is a key step for computing the supercritical heat transfer of hydrocarbon fuels. In this paper, data lists of fuel properties are created firstly according to specific temperature and pressure by a thermophysical properties evaluation code of hydrocarbon fuels (Huber, 2003). The code has been normally used for the researches on supercritical heat transfer of hydrocarbon fuels at present (Hua et al, 2010; Ward, Ervin, Steiebich, \& Zabarnick, 2004; Li et al., 2011). Figure 1 shows the thermophysical properties of $n$-decane under varied temperature. Subsequently, a look-up table method is introduced to update the fuel properties in numerical iteration process. Data lists can be reused and expanded easily and the look-up table method can promote the computational efficiency because it avoids the repeated calculation of fuel properties in the numerical calculation process. 


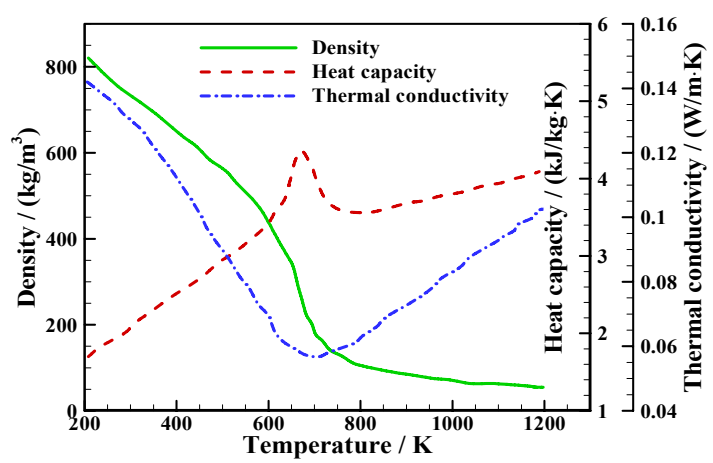

Figure 1. Thermophysical properties of $n$-decane with varied temperature under $4 \mathrm{MPa}$

The numerical calculation process is shown in Figure 2.

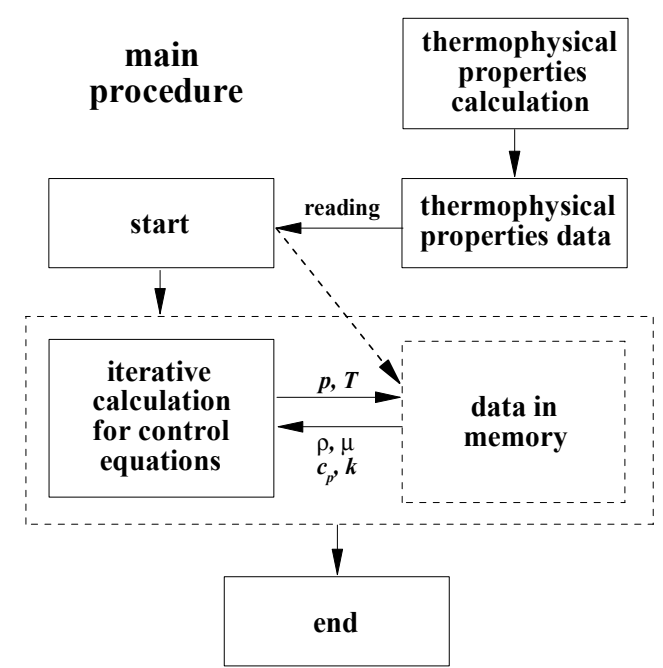

Figure 2. Numerical Calculation Process

\section{Experiments}

\subsection{Electrically Heated Tube Test}

Electrically heated tube test has some advantages such as high heat flux, quick increase of temperature and simple operating system. Consequently, it is widely adopted for the heat transfer research of hydrocarbon fuels (Linne, Meyer, \& Edwards 1997; Wishart, Fortin, \& Guinan 2003).

Figure 3 illustrates the sketch of electrically heated tube. The tube material is stainless steel (1Cr18Ni9Ti). Length, inner diameter and outer diameter of the tube are $1.3 \mathrm{~m}, 1.5 \mathrm{~mm}$ and $3 \mathrm{~mm}$ respectively. It is convenient for computation and analysis with a single-specie fuel, the thermophysical property variations of $n$-decane (critical pressure $2.11 \mathrm{MPa}$, critical temperature $617.7 \mathrm{~K}$ ) with temperature are similar to that of engine fuel. Therefore, $n$-decane is used as the working substance. The inlet temperature, pressure and flux of $n$-decane are $300 \mathrm{~K}, 4 \mathrm{MPa}$ and $1.24 \mathrm{~g} / \mathrm{s}$ respectively. The tube is heated via steady electrical current $(0-300 \mathrm{~A})$ produced by direct current supply. Different heat flux can be obtained via adjusting the electrical current. 


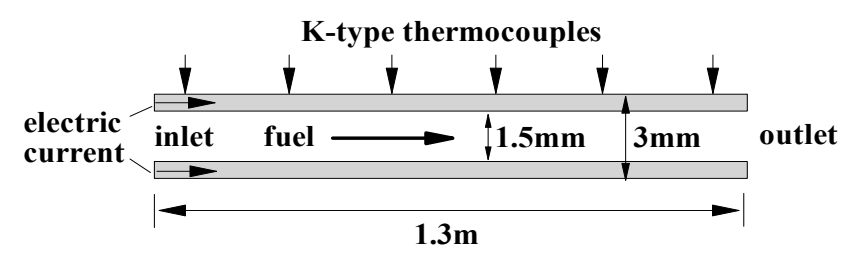

Figure 3. Computational configuration

There are seventeen K-type thermocouples welded on the tube outer wall to measure the temperature. The measured results are shown in Figure 3. Heat transfer analysis is carried out based on the conservation of energy. The heat loss consists of natural convective heat transfer of outer wall surface with environment and thermal radiation of the outer wall (L. Zhang, Le, \& R. Zhang, 2013). Subtracting the heat loss from the total input power, the net heat flux absorbed by the fuel can be obtained. For a tiny segment $i$ of the tube, the heat flux on the inner wall is evaluated by Equation (8).

$$
q_{i}=\frac{I^{2} R_{i}-\left(P_{\text {loss }}\right)_{i}}{\pi d \Delta l}
$$

Heat loss $P_{\text {loss }}$ is evaluated by Equation (9).

$$
P_{\text {loss }}=0.11\left(T_{\text {ow }}-T_{\text {air }}\right)+0.41 \times 10^{-9}\left(T_{o w}^{4}-T_{\text {air }}^{4}\right)
$$

In Equation (8), $I$ is the current intensity, $R$ represents resistance of the tube, $d$ is the inner diameter of the tube, and $\Delta l$ is the length of the tiny segment. In Equation (9), $T_{o w}$ is the outer wall temperature, and $T_{a i r}$ is the environment temperature.

The heat flux along the tube is illustrated in Figure 4.

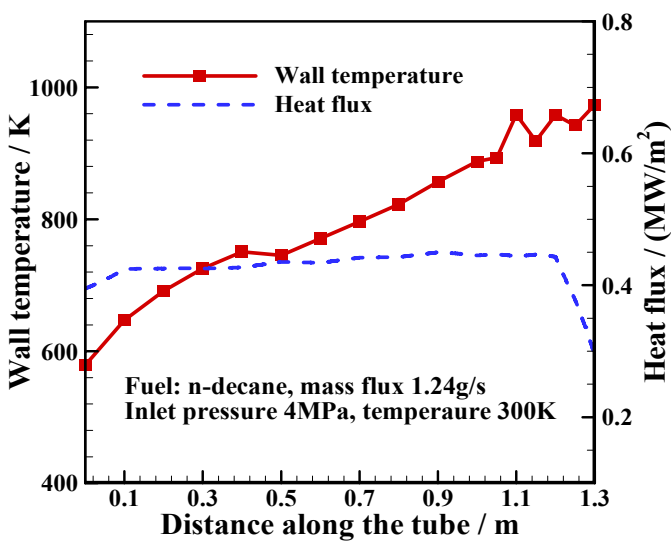

Figure 4. Outer wall temperature and heat flux along the electrically heated tube

\subsection{Fuel-Cooled Panel Test}

The test is performed on the arc heater, whose nozzle exit is rectangular, while the Ma (Mach Number) equals to 2.3. The temperature range of the heating air flow is $1850-2430 \mathrm{~K}$. There are six thermocouples welded on the backside wall of the panel to measure the temperature (see Figure 5). At the exit of the cooling channel, a K-type thermocouple is employed to measure the fuel temperature. 


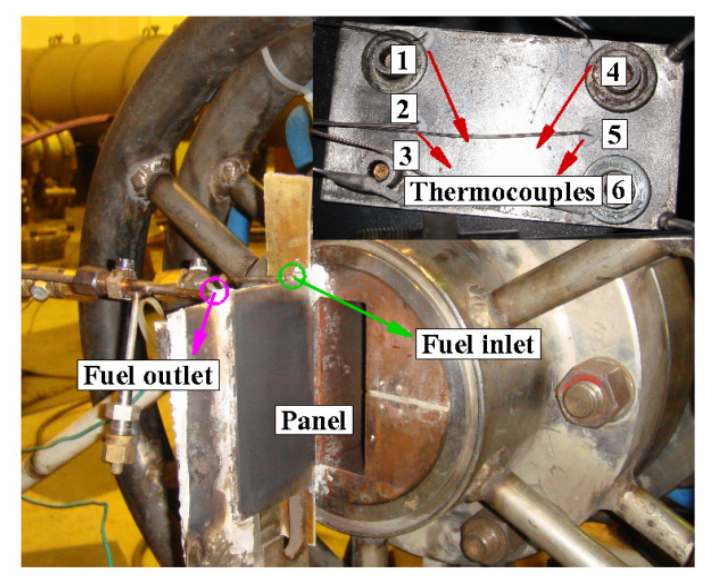

Figure 5. Fuel-cooled panel fixed on the arc heater

Pure $n$-dodecane is used as working substance, and its inlet temperature, pressure and mass flow rate are $283 \mathrm{~K}$, $5.3 \mathrm{MPa}$ and $4.17 \mathrm{~g} / \mathrm{s}$ respectively. The fuel-cooled panel, whose size is $66 \mathrm{~mm} \times 124 \mathrm{~mm}$, is manufactured by welding a cover plate (1Cr18Ni9Ti) to the channel plate (GH3030) with a snake-like cooling channel, the length of which is $2.2 \mathrm{~m}$. The thickness of cover plate is $3 \mathrm{~mm}$, and that of the channel plate is $2.3 \mathrm{~mm}$. The channel size (width $\times$ height) and rib width are $2 \mathrm{~mm} \times 1.5 \mathrm{~mm}$ and $1.5 \mathrm{~mm}$ respectively.

The structure of fuel-cooled panel is simple and the wall heat flux is approximately uniform. This simplifies the three-dimensional flow and heat transfer behavior of hydrocarbon fuels under supercritical conditions. Furthermore, the pressure, temperature, etc. can be measured easily, thus the fuel-cooled panel test is also accomplished to validate the numerical method.

Heat transfer analysis for this experiment was accomplished (Jiang et al., 2011), and the evaluated temperature distribution of the gas-side wall is illustrated in Figure 6.

\section{Results and Discussion}

After the accomplishment of the two validation experiments, the exit fuel is analyzed using chromatograph. It is found that the fuel conversion for both the tests is less than $2 \%$, and consequently, thermal cracking of the fuel is neglected in the numerical calculation process.

The computational domain of the electrically tube is shown in Figure 3, and that of the fuel-cooled panel is accordant with the sizes introduced in section 3.2. For accurately computing, there should be adequate grids in boundary layer. Mesh independence checkout has been investigated before the computation. It is found that the $y^{+}$of the first near wall node should be approximately 1 . In order to meet this condition, the normal size of the first near wall grid is $1 \mu \mathrm{m}$ in the computation. For the electrically heated tube, there are $25 \times 3000$ (radial $\times$ axial) girds on the axisymmetric plane. For the fuel-cooled panel, there are $25 \times 21$ (width $\times$ height) girds on the cross section which is vertical to the flow direction, and the total grid number is nearly 5000000 .

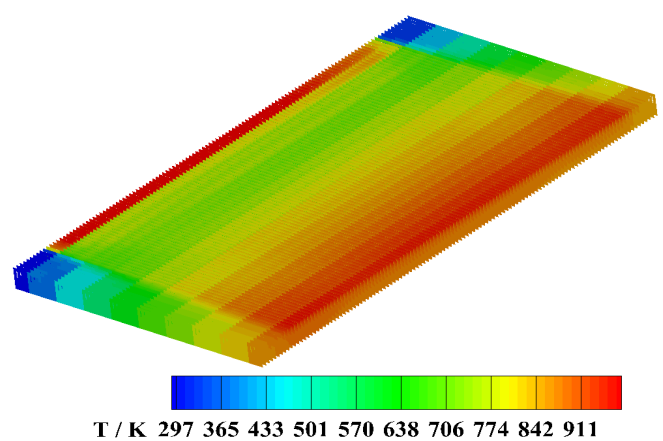

Figure 6. Gas-side wall temperature evaluated by heat transfer analysis 
Boundary conditions are defined by Equations (10)-(12).

Inlet conditions:

$$
u_{i n}=u_{0}=\frac{\dot{m}}{\rho A}, \quad T_{i n}=T_{0}, \quad \frac{\partial p}{\partial x}=0
$$

Wall conditions:

$$
u_{w}=0, \quad q_{w}=q(x), \quad \frac{\partial p}{\partial n}=0
$$

Outlet conditions:

$$
\frac{\partial u}{\partial x}=0, \quad \frac{\partial T}{\partial x}=0, \quad p=p_{0}
$$

The $A$ is the cross section area of the tube/channel. The subscript in represents the inlet. For the electrically heated tube, $q(x)$ is shown in figure 4. For the fuel-cooled panel, $q_{w}$ can be found in the investigation of Jiang et al. (2011).

The SIMPLE (Semi-Implicit Method for Pressure Linked Equations) algorithm is used to solve the pressure-velocity conjugate (Partanker, 1980). The relaxation factor of pressure is 0.3 , while it equals to 0.7 for other variables.

\subsection{Comparison With Electrically Heated Tube Test}

The computational outer wall temperature of the tube is compared with the experimental result in Figure 7. As shown in this figure, when the $l$ (distance along the tube) is less than $0.5 \mathrm{~m}$, the computational temperature shows a wide difference from the test data. One main reason could account for this phenomenon: the Re (Reynolds Number) of $n$-decane is less than 2300 at the tube entrance, representing laminar flow state. Flow transition to turbulence will happen downstream with the flow and heat transfer development of $n$-decane. It is observed that the Re rise above 10000 at about $l=0.45 \mathrm{~m}$, indicating that the flow has changed to turbulence. Since the heat transfer efficiency of laminar and transitional flow is lower than that of turbulent flow, but the flow and heat transfer of $n$-decane is computed using turbulent model for the whole tube, the calculated wall temperatures are lower than the measured ones in the range of $l \leq 0.5 \mathrm{~m}$. Figure 7 also shows an abrupt increase of the calculated temperature at the tube inlet, which could be caused by the turbulent model chose in present work, and similar results can be observed in some other researches (Hua et al, 2010; Zhou, Krishnan, \& Blvd, 1997).

The change of flow state has little influences on the temperature variation of $n$-decane, and further on the heat transfer in turbulent region. In turbulent region $(l>0.5 \mathrm{~m})$, the relative deviation of computational temperature from the test data, calculated by $\Delta T /\left(T_{w}-T_{0}\right)$, is within $1 \%$.

\subsection{Comparison With Fuel-Cooled Panel Test}

The computational wall temperature of the panel is illustrated in Figure 8. Comparing with the result of heat transfer analysis shown in figure 6 , the maximum difference is $21.5 \mathrm{~K}$ and the percentage deviation relative to the increase of wall temperature (about $711 \mathrm{~K}$ ) is $3 \%$. Figure 9 shows the fuel temperature on the symmetry plane of cooling channel.

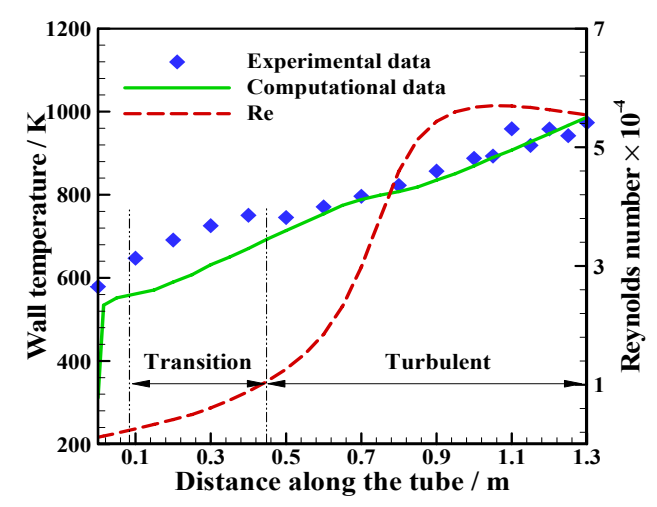

Figure 7. Distribution of Reynolds number and comparison of outer wall temperature 


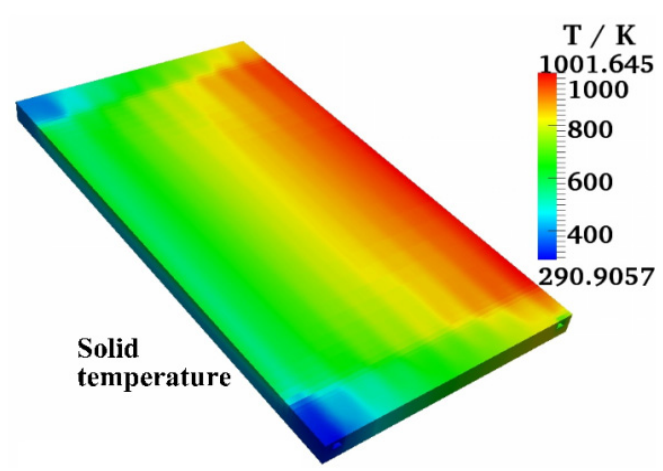

Figure 8. Computational temperature distribution of the solid wall

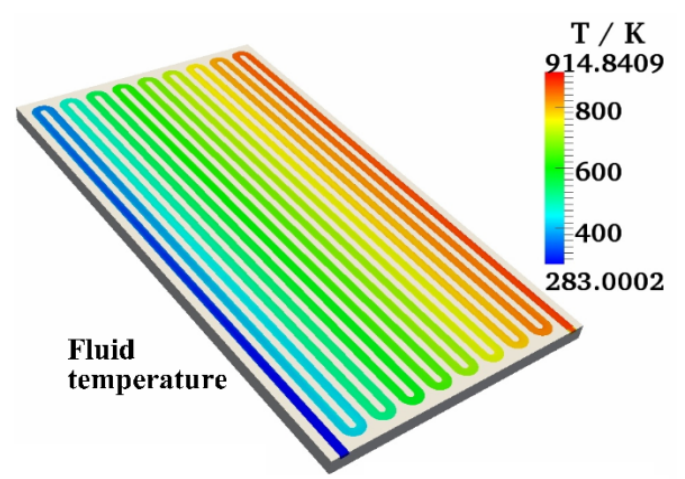

Figure 9. Distribution of n-dodecane temperature on the symmetry plane of cooling channel

Figure 10 shows the backside wall temperature at the location where the thermocouples are jointed. Since the inlet Re of $n$-dodecane is less than 2300 , the flow state is laminar and flow transition will happen downstream. Based on the same reason mentioned in section 4.1, the results for thermocouples 1 and 4, which are in laminar and transitional region, are not used for the validation of the numerical method. As illustrated in Figure 10, in turbulent region (thermocouples 5, 2, 6 and 3), the absolute deviation of computational temperature from the heat transfer analysis is $38 \mathrm{~K}$, about $5.2 \%$ relative to the increase margin of wall temperature.

Some thermocouples have dropt down in the experiment process because of the uncertainty of measurement technique under high temperature conditions. Only the measured data of thermocouple 3 is effective and it is shown in Figure 10. The measured wall temperature of thermocouple 3 is within the range of 822-870 K when the test reaches to thermal balance, while the calculated result is $878 \mathrm{~K}$. The relative deviation between computation and experiment is in the range of $0.92-6.8 \%$.

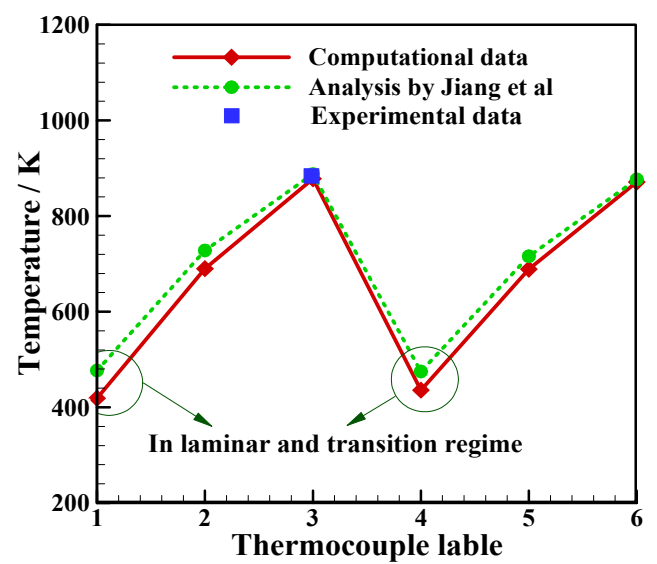

Figure 10. Comparison of the backside wall temperature at the location corresponding to the thermocouples

Moreover, the calculated temperature of $n$-dodecane at the panel exit is $876 \mathrm{~K}$. Comparing with the results of heat transfer analysis $(879 \mathrm{~K})$ and measurement $(871 \mathrm{~K})$, the difference of the fuel temperature is $3 \mathrm{~K}$ and $5 \mathrm{~K}$ respectively, while the relative deviations are all within $1 \%$.

\section{Conclusions}

The main conclusions obtained from this investigation are described as follows:

(i) A three-dimensional numerical method for supercritical heat transfer of hydrocarbon fuels is established based on Navier-Stokes equations and a thermophysical properties evaluation code. The method can be used to compute laminar/turbulent and low-speed flow, and fluid-solid conjugated heat transfer of hydrocarbon fuels with varied thermophysical properties under supercritical conditions. 
(ii) Electrically heated tube test and fuel-cooled panel test are conducted to validate the numerical method. In turbulent region, the relative deviations of computational outer wall temperature for the electrically heated tube from the measurement ones are within 1\%. For the fuel-cooled panel, the relative deviations of wall and fuel temperature are about $6.8 \%$ and $1 \%$ respectively. Those indicate that the numerical method is accurate and reliable.

(iii) The numerical method developed in this paper can be used to investigate the regenerative cooling mechanism for the hydrocarbon-fueled scramjet.

\section{References}

Palaszewski, B., Ianovski, L. S., \& Carrick, P. (1998). Propellant technologies: far-reaching benefits for aeronautical and space-vehicle propulsion. Journal of Propulsion and Power, 14, 641-648. http://dx.doi.org/10.2514/2.5356

Huang, H., Spadaccini, L. J., Sobel, D. R. (2004). Fuel-cooled thermal management for advanced aeroengines. Journal of Engineering for Gas Turbines and Power, 126, 284-293. http://dx.doi.org/10.1115/1.1689361

Zhong, F. Q., Fan, X. J., Yu, G., Li, J. G., Lu, X. N., \& Sung, C. J. (2008). Heat transfer of aviation kerosene at supercritical conditions. AIAA, 2008-4615. http://dx.doi.org/10.2514/6.2008-4615

Hua, Y. X., Wang, Y. Z., \& Meng, H. (2010). A numerical study of supercritical forced convective heat transfer of $n$-heptane inside a horizontal miniature tube. The Journal of Supercritical Fluids, 52, 36-46. http://dx.doi.org/10.1016/j.supflu.2009.12.003

Dang, G. X., Zhong, F. Q., Chen, L. H., \& Zhang, X. Y. (2013). Numerical investigation on flow and convective heat transfer of aviation kerosene at supercritical conditions. Science in China Series E: Technological Sciences, 56, 416-422. http://dx.doi.org/10.1007/s11431-012-5075-3

Menter, F. R. (1994). Two-equation eddy-viscosity turbulence models for engineering applications. AIAA Journal, 32, 1598-1605. http://dx.doi.org/10.2514/3.12149

Huber, M. L. (2003). NIST standard reference database 4-NIST thermophysical properties of hydrocarbon mixtures database (SUPERTRAPP), version 3.1. National Institute of Standards and Technology, Gaithersburg, MD.

Ward, T. A., Ervin, J. S., Striebich, R. C., \& Zabarnick, S. (2004). Simulations of flowing middly-cracked normal alkanes incorporating proportional products distribution. Journal of Propulsion and Power, 20, 394-402. http://dx.doi.org/10.2514/1.10380

Li, X. F., Huai, X. L., Cai, J., Zhong, F. Q., Fan, X. J., \& Guo, Z. X. (2011). Convective heat transfer characteristics of China RP-3 aviation kerosene at supercritical pressure. Applied Thermal Engineering, 31, 2360-2366. http://dx.doi.org/10.1016/j.applthermaleng.2011.03.036

Linne, D. L., Meyer, M. L., \& Edwards, T. (1997). Evaluation of heat transfer and thermal stability of supercritical JP-7 fuel. AIAA, 97-3041. http://dx.doi.org/10.2514/6.1997-3041

Wishart D.P., Fortin T., Guinan D. (2003). Design fabrication and testing of an actively cooled scramjet propulsion system. AIAA, 2003-15. http://dx.doi.org/10.2514/6.2003-15

Zhang, L., Le, J. L., \& Zhang, R. L. (2013). Heat transfer of hydrocarbon fuel in turbulent flow region under supercritical pressure. Journal of Propulsion Technology (in Chinese), 34, 225-229

Jiang, J., Zhang, R. L., Le, J. L., Liu, W. X., Wu, J., \& Zhao, G. Z. (2011). The investigation on heat transfer characteristic tests and thermal evaluation of fuel-cooled panels. Journal of Experiments in Fluid Mechanics (in Chinese), 25, 1-7

Partanker, S. V. (1980). Numerical heat transfer and fluid flow. New York: McGraw-Hill.

Zhou, N., Krishnan, A., \& Blvd, T. (1997). Numerical simulation of jet fuel heat transfer and deposition at supercritical pressure. AIAA, 97-3042. http://dx.doi.org/10.2514/6.1997-3042

\section{Copyrights}

Copyright for this article is retained by the author(s), with first publication rights granted to the journal.

This is an open-access article distributed under the terms and conditions of the Creative Commons Attribution license (http://creativecommons.org/licenses/by/3.0/). 